\title{
An aborted case suspected to CHARGE Syndrome; A rare case with cardiac, intestinal and kidney abnormalities
}

\author{
Shahriar Ahmadpour ${ }^{*}$ (D) Khadijeh Foghi and Faezeh Rezaei
}

\begin{abstract}
Background: CHARGE syndrome is a life-threatening congenital anomaly. The syndrome associations consist of coloboma, heart disease, atresia of the choanae, retarded growth and development, genital hypoplasia/genitourinary anomalies, and ear anomalies and or hearing loss. The aim of this paper is to describe and discuss a rare case of CHARGE syndrome.

Case presentation: During the routine dissection, atrial septal defect, overriding aorta from both ventricles, patent ductus arteriosus, duodenal anomaly, absent pancreas, right side descending and sigmoid, intestinal herniation in lesser sac, and left kidney anomaly were observed.

Conclusions: This rare case is of importance in re-considering the criteria of CHARGE and understanding the importance of the orchestrated morphologic driving forces of embryonic development.
\end{abstract}

Keywords: CHARGE syndrome, Multicystic kidney, Atrial septal defect

\section{Background}

CHARGE syndrome or Hall-Hittner syndrome is a rare multiple congenital anomaly syndrome that can be life threatening in the neonatal period. Complex heart defects, bilateral choanal atresia, esophageal atresia, severe $\mathrm{T}$ cell deficiency, and brain anomalies can cause neonatal death (Bergman et al. 2010; Graham 2001; Usman and Sur 2020). The CHARGE association criteria were originally proposed by Pagon (Pagon et al. 1981). Nowadays, it is defined as major, minor, and occasional criteria. Major criteria are those findings that occur commonly in CHARGE syndrome but are relatively rare in other conditions. The minor criteria occur less frequently or are less specific to CHARGE syndrome (Blake and Prasad 2006). Major criteria include ocular coloboma, choanal atresia/stenosis, cranial nerve anomalies, and ear anomalies. Minor criteria are characterized with

*Correspondence: sobar1975@hotmail.com

Anatomical Sciences Department, Medicine School, North Khorasan University of Medical Sciences, Bojnurd, Iran cardiovascular anomalies such as Fallot tetralogy, genital hypoplasia, orofacial cleft, and tracheoesophageal fistula (Anderzén-Carlsson 2015). Here, we are reporting a CHARGE syndrome with cardiac outflow tract anomalies and severe intestinal and renal malformations.

\section{Case presentation}

During a routine educational dissection of a donated 22 weeks' male fetus with prenatal diagnosed CHARGE syndrome, a wide spectrum of multiple anomalies was observed. The prenatal diagnosis of CHARGE syndrome was confirmed based on tympanic ring anomaly and also on mother's coloboma history. The mother had no history of infectious disease during pregnancy or metabolic disorders. The fetus was transferred to the dissecting lab. All protocols were done according to the ethics and regulation of research with human subjects of North Khorasan University of Medical Sciences. The dissection was conducted from superficial to deep planes. Firstly, the skin and subcutaneous tissue were removed and thoracic cavity contents exposed. Then, heart and lungs 
were dissected and examined meticulously. Next step, the abdominal wall was dissected and peritoneal cavity exposed carefully. We observed a series of cardiac, gastrointestinal, and renal anomalies. Heart dissection revealed atrial septal defect (ASD) (Fig. 1). Aortic orifice overrode from both ventricles (Fig. 2). Pulmonary trunk and aorta were not fully separated (3). Then, the abdominal wall was dissected carefully, and the viscera were inspected (Fig. 3). Descending duodenum (second portion) ended to a closed pouch, and pancreas was absent (Fig. 4). The ascending colon was absent while the descending colon and sigmoid displaced to the right side (Fig. 4). Parts of small intestine herniated into lesser sac, which was exposed after dissecting the attachment of greater omentum to the stomach (Fig. 4). Further inspection revealed that the parietal peritoneum on the kidneys on both side were absent, and the left kidney was cystic (Fig. 5).

\section{Discussion}

CHARGE syndrome (CS) is known for causing a wide variety of developmental anomalies. There are many reports that have dealt with CS extensively (Sánchez et al. 2019; van Ravenswaaij-Arts and Martin 2017; de Geus et al., 2017; Hudson et al. 2017; Blake et al. 1998). In 1998, a group of experts defined major and minor criteria of CS (Blake et al., 1998). Accordingly, major criteria or 4Cs include coloboma, choanal atresia, cranial nerve anomalies, and characteristic ear anomalies. Minor criteria are

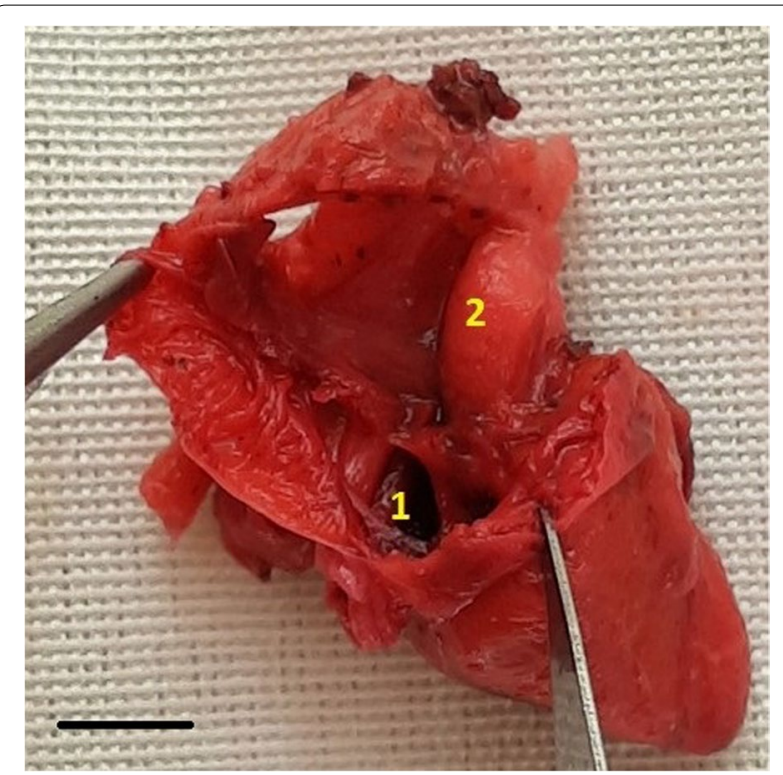

Fig. 1 Dissected right atrium. Interatrial septal defect (1) and prominent torus aorticus. The ascending aorta displaced to the right atrium. Scale bar $0.5 \mathrm{~cm}$

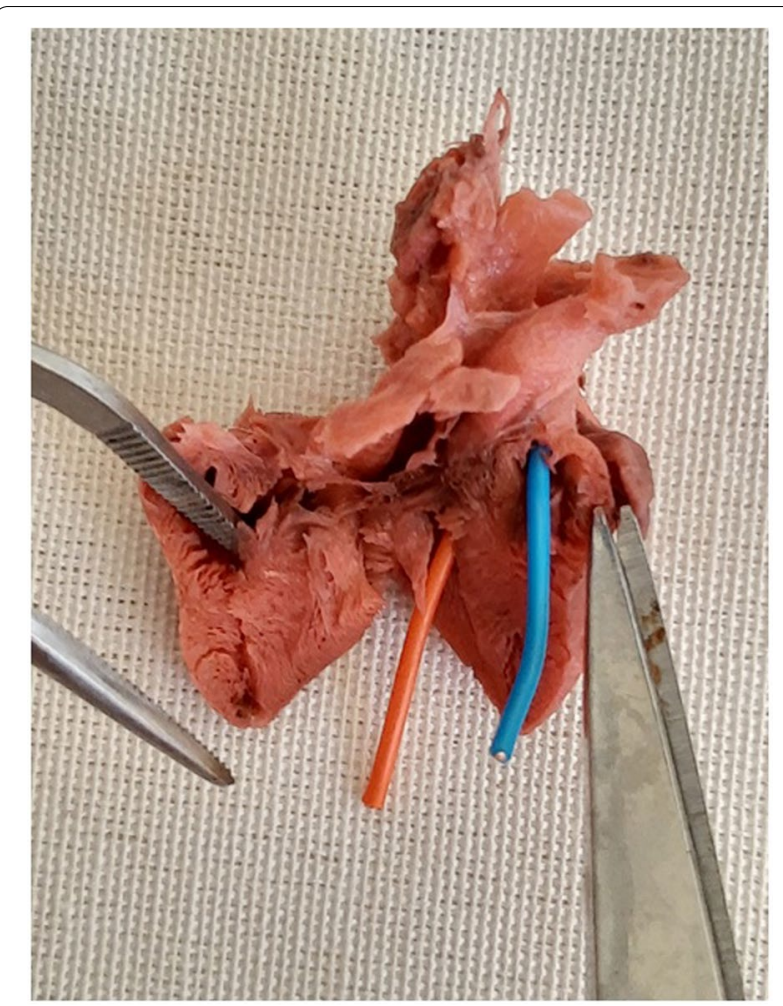

Fig. 2 Right ventricle exposed. The orifice of aorta (orange probe) opened to the right ventricle. Pulmonary trunk is shown with blue probe. Scale bar $0.5 \mathrm{~cm}$

cardiovascular malformations, genital hypoplasia, cleft lip/palate, and tracheoesophageal fistula. Additionally, there is a third group of criteria, occasional findings, that are more prevalent than originally predicted (Issekutz et al., 2005; Schussler et al. 2021). Occasional findings involve musculoskeletal anomalies and malformation. The case we presented showed cardiac anomalies, gastrointestinal malrotation, visceral herniation, and unilateral kidney anomaly. Considering the plethora of clinical case report and series, the presented case will be discussed from developmental perspective. Cardiac development is a complex dynamic process which begins at the 4th week. Dynamics of the developing heart, in particular compartmentalization of cardiac cavity and vascular septation, are not merely governed by cardiac tissue cellular factors, but there are extrinsic factors migrating to developing heart such as neural crest cells (Morton et al. 2017). Additionally, recent findings have provided compelling evidence that indicate the link between the neurodevelopment with congenital heart diseases (Webb et al. 2003). In this case, atrial septal defect (ASD), displaced aortic orifice, and persisted aortico-pulmonary trunk were noticed. Although the mechanism underlying cardiac outflow septation remains controversial, the structure 


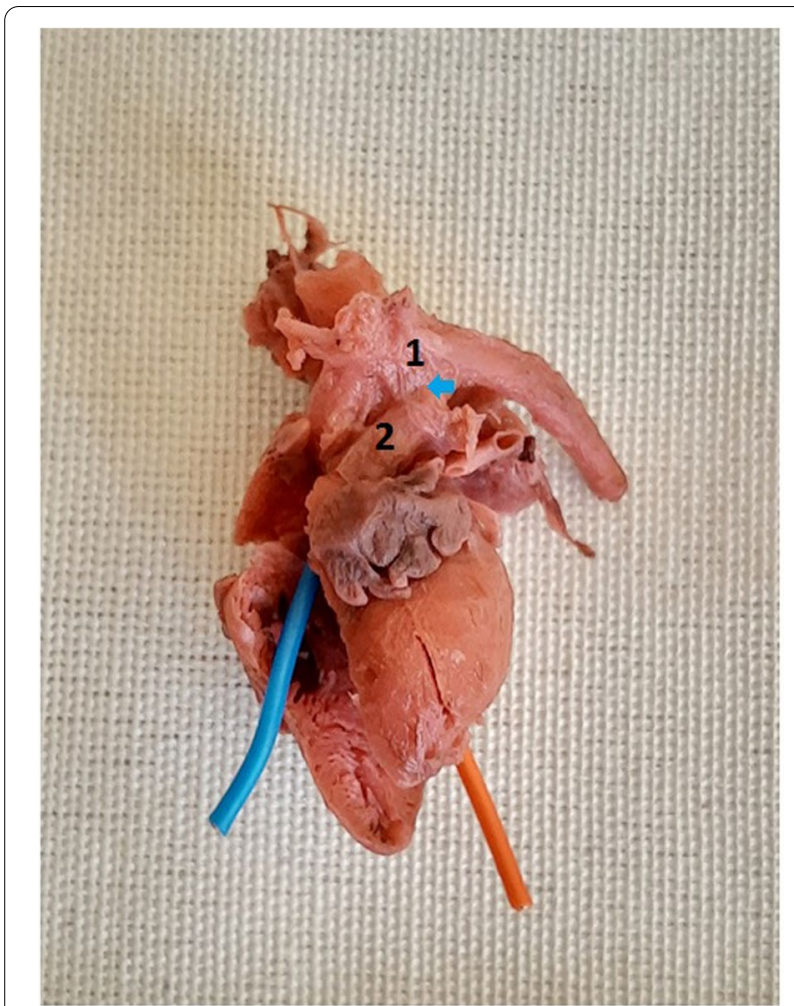

Fig. 3 Patent ductus arteriosus. Aortic arch (1) and pulmonary trunk (2) are not completely separated. Scale bar $0.5 \mathrm{~cm}$

often referred to as the aorto-pulmonary (AP) septum has been suggested to play key roles during separation of the initially single outflow vessel to form the ascending aorta and the pulmonary trunk (Henderson et al. 2020; Bradshaw et al. 2009). Study by Bradshaw et al. (2009) showed that neural crest cell contributes actively to cardiac out flow development. Neeb et al. (2013) classified cardiac out flow tract (OFT) anomalies into four major types. These anomalies include overriding aorta (OA), transposition of great arteries (TGA), double outlet right ventricle (DORV), and persistent truncus arteriosus (PTA). Accordingly, the presented case can be classified as a mixed type of DROV and PTA. Besides the OFT anomalies, ASD should also be added to these anomalies. To the best of our knowledge, this variant of cardiac anomalies has not been reported by previous studies. Another group of findings were severe gastrointestinal abnormalities. Herniated intestinal lopes in the lesser sac, right side descending colon, duodenal pouch, absence of pancreas, and left cystic kidney were the major findings. The parts of the large intestine derive from the midgut and hindgut. By 10 weeks, the abdomen has developmentally enlarged sufficiently so that the entire midgut can be accommodated inside it. Following a further $180^{\circ}$ counterclockwise rotation around the superior mesenteric

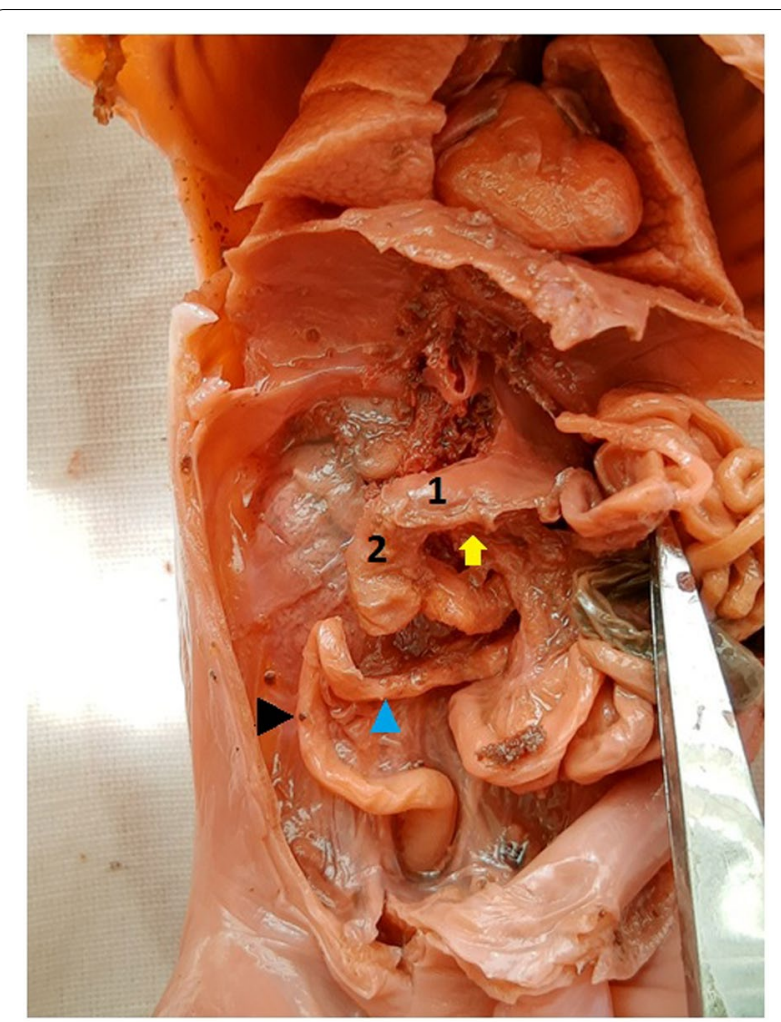

Fig. 4 Left side descending colon (black arrowhead). Transverse colon (blue arrowhead). Greater omentum has been removed. Part of intestine trapped in lesser sac (yellow arrow). The stomach reflected upward (1). Second part of duodenum (2) ended to closed pouch. Scale bar $0.5 \mathrm{~cm}$

artery, the small intestine returns to the abdominal cavity. Concurrently, the large intestine follows its rotation and also moves $180^{\circ}$ counterclockwise. Following the return of midgut in the abdomen, the mesenteries of cecum and ascending colon fix to the dorsal wall, making these parts immobile (Park et al. 2005; Kluth et al. 2003; Kostouros et al. 2020). Although the molecular and structural interactions involved in intestinal rotation that promote the phenomenon of rotation have not been investigated in detail, there is evidence to indicate that the dorsal mesentery of the midgut loop presents molecular and architectural left-right asymmetry. For instance, the transcriptional factor Pitx-2is restrictedly expressed in the left side of the dorsal mesentery in its whole dorsal-ventral extent, and reversed intestinal rotation (RIR) could affect the proper succeeding development of GI glands such as the pancreas (Pandya and Sutariya 2017). Additionally, RIR as reported in this case was associated with duodenal anomaly and absent of pancreas. These are one of the rarest forms of anomalies that have been reported. RIR associated with structural duodenal anomaly, absent pancreas, and lesser sac herniation implicitly 


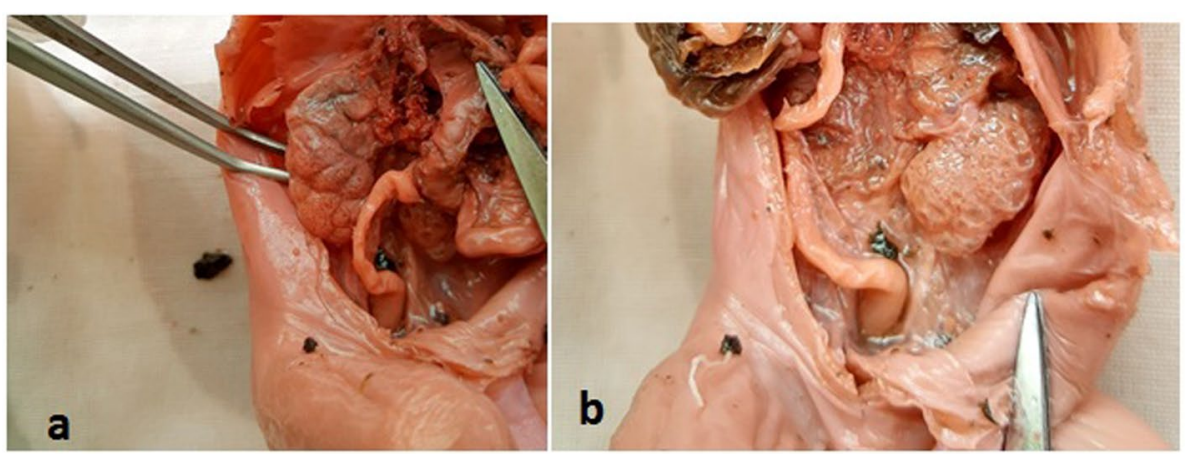

Fig. 5 Right kidney (a) elevated with forceps. Left kidney (b) is cystic. Scale bar $0.5 \mathrm{~cm}$

denote to orchestrate whole gut development which is governed by genes products and molecular gradients. Another finding was unilateral cystic kidney. Multicystic kidney is the most common antenatally diagnosed cystic renal pathology. It refers to the presence of multiple renal cysts surrounded by dysplastic parenchymal tissue. This anomaly may be explained by an abnormal induction of metanephric blastoma by the migrating ureteric bud. It has been proposed that displaced metanephric blastoma interspersed with normal zones of nephrogenes generates the irregular parenchyma of the multicystic kidney. The subsequent cystic dilatation of dysplastic tissue compresses and permanently damages the normal renal tissue. GHARGE syndrome is a complex genetic syndrome which affects multiple system and organs. According to the Blake criteria (Blake et al. 2002), despite the sonography report indicating to CHRAGE syndrome, we could not find major criteria such as coloboma and choanal atresia. Also, due to some limitation, we could not find characteristic ear fine structures anomalies.

\section{Conclusions}

Although the case was diagnosed as CHARGE syndrome according to the sonography report (low tympanic ring) and maternal history, autopsy findings revealed a wide spectrum of abnormalities. Here, we reported association of some anomalies which have been less noticed. The classifications and diagnosis of CHARGE syndrome are generally based on the phenotypic features, while suspected cases are often missed. The findings presented here are of importance in re-considering the prenatal sonographic criteria of CHARGE and understanding the importance of the orchestrated morphologic driving forces of embryonic development.

\section{Abbreviations}

ASD: Atrial septal defect; AP: Aorto-pulmonary; CS: CHARGE syndrome; DORV: Double outlet right ventricle; PTA: Persistent ductus arteriosus; OA: Overriding aorta; OFT: Out flow tract; TGA: Transposition of great arteries; RIR: Reversed intestinal rotation.

\section{Acknowledgements}

The authors sincerely thank those who donated their bodies to science so that anatomical research and teaching could be performed. Results from such research can potentially increase scientific knowledge and can improve patient care. Therefore, these donors and their families deserve our highest respect.

\section{Authors' contributions}

The first author and corresponding author performed the autopsy, diagnoses, preparation of the manuscript outlines, and writing and submitting. Co-authors of this autopsy case presentation had contribution in the autopsy procedure and searching of the materials. The authors read and approved the final manuscript.

\section{Funding}

Not applicable

\section{Availability of data and materials}

Data available within the article and its supplementary materials are available on request at autopsy lab.

\section{Declarations}

Ethics approval and consent to participate Not applicable

\section{Consent for publication}

Permission for publication was approved by ethic committee of research deputy of medicine school.

\section{Competing interests}

The authors declare that they have no competing interests.

Received: 16 September 2021 Accepted: 29 November 2021

Published online: 20 December 2021

\section{References}

Anderzén-Carlsson A (2015) CHARGE syndrome-a five case study of the syndrome characteristics and health care consumption during the first year in life. J Pediatr Nurs 30(1):6-16. https://doi.org/10.1016/j.pedn.2014. 09.008

Bergman JE, Blake KD, Bakker MK, du Marchie Sarvaas GJ, Free RH, van Ravenswaaij-Arts CM (2010) Death in CHARGE syndrome after the neonatal period. Clin Genet 77(3):232-240. https://doi.org/10.1111/j.1399-0004. 2009.01334.x 
Blake KD, Davenport SL, Hall BD, Hefner MA, Pagon RA, Williams MS, Lin AE, Graham JM Jr (1998) CHARGE association: an update and review for the primary pediatrician. Clin Pediatr 37(3):159-173. https://doi.org/10.1177/ 000992289803700302

Blake, K. D., Issekutz, K.A., Smith, I.M., Prasad, C., Graham, JM. JR (2002). The incidence and prevalence of CHARGE syndrome. The CPSP annual report. https://www.CPS.ca

Blake KD, Prasad C (2006) CHARGE syndrome. Orphanet J Rare Dis 1:34. https:// doi.org/10.1186/1750-1172-1-34

Bradshaw L, Chaudhry B, Hildreth V, Webb S, Henderson DJ (2009) Dual role for neural crest cells during outflow tract septation in the neural crestdeficient mutant splotch(2H). J Anat 214(2):245-257. https://doi.org/10. 1111/j.1469-7580.2008.01028.x

de Geus CM, Free RH, Verbist BM, Sival DA, Blake KD, Meiners LC, van Ravenswaaij-Arts C. (2017) Guidelines in CHARGE syndrome and the missing link: Cranial imaging. Am J Med Genet C Semin Med Genet 175(4):450464. https://doi.org/10.1002/ajmg.c.31593.

Graham JM Jr (2001) A recognizable syndrome within CHARGE association: Hall-Hittner syndrome. Am J Med Genet 99(2):120-123 (https://doi.org/ 10.1002/10.1002/1096-8628(2000)9999:999<00::aid-ajmg1132>3.0.co;2-j)

Henderson DJ, Eley L, Chaudhry B (2020) New concepts in the development and malformation of the arterial valves. J Cardiovasc Dev Dis 7(4):38 https://doi.org/10.3390/jcdd7040038

Hudson A, Trider CL, Blake K (2017) CHARGE syndrome. Pediatr Rev 38(1):5659. https://doi.org/10.1542/pir.2016-0050

Issekutz KA, Graham JM Jr, Prasad C, Smith IM, Blake KD (2005) An epidemiological analysis of CHARGE syndrome: preliminary results from a Canadian study. Am J Med Genet A 133A(3):309-317. https://doi.org/10.1002/ ajmg.a.30560

Kluth D, Jaeschke-Melli S, Fiegel H (2003) The embryology of gut rotation. Semin Pediatr Surg 12(4):275-279. https://doi.org/10.1053/j.sempedsurg. 2003.08.009

Kostouros A, Koliarakis I, Natsis K, Spandidos DA, Tsatsakis A, Tsiaoussis J (2020) Large intestine embryogenesis: molecular pathways and related disorders (review). Int J Mol Med 46(1):27-57. https://doi.org/10.3892/ ijmm.2020.4583

Morton PD, Ishibashi N, Jonas RA (2017) Neurodevelopmental abnormalities and congenital heart disease: insights into altered brain maturation. Circ Res 120(6):960-977. https://doi.org/10.1161/CIRCRESAHA.116.309048

Neeb Z, Lajiness JD, Bolanis E, Conway SJ (2013) Cardiac outflow tract anomalies. Wiley interdisciplinary reviews. Dev Biol 2(4):499-530. https://doi.org/ 10.1002/wdev.98

Pagon RA, Graham JM Jr, Zonana J, Yong SL (1981) Coloboma, congenital heart disease, and choanal atresia with multiple anomalies: CHARGE association. J Pediatr 99(2):223-227. https://doi.org/10.1016/s0022-3476(81) 80454-4

Pandya VK, Sutariya HC (2017) Unilateral multicystic renal dysplasia: prenatal diagnosis on ultrasound. Saudi J Kidney Dis Transpl 28(4):916-920

Park JJ, Wolff BG, Tollefson MK, Walsh EE, Larson DR (2005) Meckel diverticulum: the Mayo Clinic experience with 1476 patients (1950-2002). Ann Surg 241(3):529-533. https://doi.org/10.1097/01.sla.0000154270.14308.5f

Sánchez N, Hernández M, Cruz JP, Mellado C (2019) Phenotypic spectrum of neonatal CHARGE syndrome. Espectro fenotípico de Síndrome de CHARGE neonatal. Rev Chil Pediatr 90(5):533-538. https://doi.org/10. 32641/rchped.v90i5.1080

Schussler O, Gharibeh L, Mootoosamy P, Murith N, Tien V, Rougemont AL, Sologashvili T, Suuronen E, Lecarpentier Y, Ruel M (2021) Cardiac neural crest cells: their rhombomeric specification, migration, and association with heart and great vessel anomalies. Cell Mol Neurobiol 41(3):403-429. https://doi.org/10.1007/s10571-020-00863-w

Usman N, Sur M (2020) CHARGE syndrome. In: Stat pearls, 1st edn. Stat Pearls Publishing, Treasure Island

van Ravenswaaij-Arts C, Martin DM (2017) New insights and advances in CHARGE syndrome: diagnosis, etiologies, treatments, and research discoveries. American journal of medical genetics. Part C, Semin Med Genet 175(4):397-406. https://doi.org/10.1002/ajmg.c.31592

Webb S, Qayyum SR, Anderson RH, Lamers WH, Richardson MK (2003) Septation and separation within the outflow tract of the developing heart. J Anat 202(4):327-342. https://doi.org/10.1046/j.1469-7580.2003.00168.x

\section{Publisher's Note}

Springer Nature remains neutral with regard to jurisdictional claims in published maps and institutional affiliations.

\section{Submit your manuscript to a SpringerOpen ${ }^{\circ}$ journal and benefit from:}

- Convenient online submission

- Rigorous peer review

- Open access: articles freely available online

High visibility within the field

- Retaining the copyright to your article

Submit your next manuscript at $\boldsymbol{\nabla}$ springeropen.com 